\title{
Give way to the ambulance; What we all need to do to facilitate ambulance in traffic?
}

\author{
Saba Tariq ${ }^{\mathrm{a}}$, Sundus Tariq ${ }^{\mathrm{b}}$, Akram Malik ${ }^{\mathrm{c}}$ \\ aProfessor, Department of Pharmacology \& Therapeutics, University Medical \& Dental College Faisalabad.

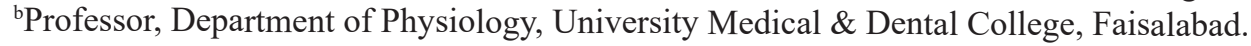

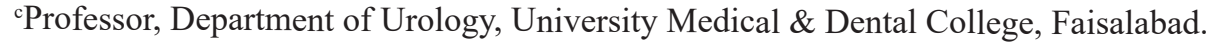 \\ *Corresponding author: drsabatariq1@gmail.com
}

Tariq S, Tariq S, Malik A. Give way to the ambulance; What we all need to do to facilitate ambulance in traffic?. Journal of University Medical \& Dental College. 2021;12(4):vii-ix.

\section{Attribution 4.0 International (CC BY 4.0)}

The sirens and lights of the ambulance are not a good sign to see. It indicates that someone's life is in danger and requires immediate medical attention. No one can comprehend the anguish and sorrow that a person's relative is experiencing at that time. Therefore, it is important to analyze various factors related to delay in emergency care from an ambulance as its own, and factors related to delay in providing treatment because of heavy traffic and ignorance of the people to give way to the ambulance.

In accordance with the "Golden Hour" theory, in order to increase the survival of a road traffic accident victim or a heart disease patient, must be taken to the health care facility within an hour of the incident, which enhances his chances of recovery by 70 to 80 percent. "Golden Hour" theory of the World Health Organization (World Health Organization) is followed all over the world ${ }^{[1]}$. It was very disheartening to see that there were very few data available in Pakistan that could tell us about how many peoples lost their lives due to delay in an ambulance reaching the hospital. In a recently conducted study to see various reasons underlying drivers' unwillingness to give way to ambulances on urban roads. They found that drivers with a lower level of education and no prior experience with emergency medical services were more hesitant to give way to ambulances than others. Drivers' self-reported readiness to not give way to ambulances was highly influenced by their attitude, perceived behavioral control, moral norms, anticipated action regret, and anticipated inactivity regret ${ }^{[2]}$.

In a quasi-experimental study, focusing on the objective of determining the campaign's effectiveness to increase the percentage of vehicles that make way for ambulances. An information campaign was organized on a mass level to raise public awareness on the importance of providing a way to ambulances. This study was conducted in Karachi, Pakistan, and in this study, three observational surveys were carried by trained observers in different parts of the city. The experts recorded the results of before, during, and after surveys on a checklist, taken at three different times of day for two days on each road. The main reasons that came out from 245 analyzed observations were overcrowding of the traffic and carelessness or resistance on the part of the drivers who were driving before the ambulances. Traffic block caused by sudden brakes of small buses and active VIP movements was a few of the other reasons causing hindrance on passage of ambulances. The survey concluded that changing the negligent behavior of people by organizing mass media campaigns and giving compassionate, humane messages in the media like "giving way to ambulances can save lives" is one of the solutions to this problem ${ }^{[3]}$.

In another study, researchers were keen to determine ways for better transportation to improve maternal, newborn and child health in Pakistan. The conclusion was made that better access to health facilities by effective referral linkages and improving the transport facilities can ameliorate maternal and child health in Pakistan. A system of integrated vouchers with community services can improve the use of services ${ }^{[4]}$. Similarly, in another study the scientist conducted a survey through Pakistan National Emergency Departments Surveillance (Pak-NEDS). Active pilot surveillance was administered in 7 tertiary-care emergency departments of 6 main cities of Pakistan. Out of 274,436 enrolled patients, the way they approached the Emergency departments (EDs) was recorded for $94.9 \%$, of which $4.1 \%$ approached EDs through ambulances. A significant difference between the mean ages of an ambulance and the non - ambulance group was seen $(38 \pm 18.4$ years versus $32.8 \pm 14.9$ years, $\mathrm{p}<0.001)$. The patients of the ambulance group came with the main complaint of head injury (12\%), while the fever was the main presenting complaint of the non-ambulance group $(12 \%)$. Patients of all age groups were less likely to use an ambulance compared to those $>45$ years of age ( $<<0.001)$. The odds of ambulance use by patients with injuries were 3.5 times more as compared to non-injured patients $(\mathrm{p}<0.001)$. 
Patients brought to the ED by ambulance were 7.2 times more likely to die in the ED than non-ambulance patients. They concluded in their research that the use of ambulances in Pakistan is very limited. Ambulances were commonly used for elderly or injured patients, and there is greater mortality of these patients in the ED who were brought by ambulances ${ }^{[5]}$. This research throws a big question that why patients coming in an ambulance are more likely to die in the emergency department. The dilemma in Pakistan is that the government and most of the private hospitals have failed to provide ambulances according to international standards. The emergency treatment that can be provided in the ambulance could not be done as these ambulances lack the equipment to do so, and therefore they are merely playing a role as to provide the mode of transport. In a study, the researchers wanted to look into the quality and accessibility of pre-hospital care on Pakistani civic roads. The study was undertaken on a 592-km-long National highway in Sindh, a province of Pakistan. The deficiencies noted during the study were more time span to reach a tertiary care hospital, that is, around 31 to 70 minutes, no triaging (86\%), informing hospitals $(64 \%)$, or recording response times $(57 \%)$. The facility of the stretcher was there in all ambulances $(\mathrm{n}=12)$, but only a few had oxygen cylinders (58\%). These deficiencies can be overcome by making lasting public-private partnerships whose aim should be to train health care providers, provision of necessary medical supplies, and connect ambulance stations with designated healthcare facilities for appropriate road traffic incident triage ${ }^{[6]}$. It was quite shocking to see that only $58 \%$ of the ambulances had oxygen cylinders, whereas none of them had portable defibrillators. Just by providing defibrillators in the ambulances, we can save hundreds of ischemic heart disease patients dying from ventricular arrhythmias.

These factors can be overcome mainly if the government provides sufficient funds to the hospitals and installs this lifesaving equipment in the ambulances. The important question here is that what we can do on our part in order to save the lives of the patients in the ambulances and to prevent the delay of ambulances in reaching the hospitals. The government, by law, has given some special rights to the emergency vehicle so that unnecessary delay can be prevented and the lives of the patients can be saved.

Fortunately, there is an act in law by the name of "Right of way to emergency rescue vehicles and ambulances." According to this law, every person who is driving any vehicle on the road should make every effort to provide untroubled and smooth passage to an ambulance with active sirens or warning lights and to any rescuer who is acting under this act ${ }^{[7]}$.

All these laws and measures have been taken in order to prevent delays in an ambulance reaching the hospital. In a study conducted in India, special traffic volume surveys were conducted to identify the existing situation and the problems faced by the users. Furthermore, this survey was also useful for analyzing the parameters like peak hour, pedestrian behavior type, and the number of peak-hour ambulances travelling on roads. In the next step, they designed the network. In network designing, two steps were involved. The initial stage was to determine the origin (hospital) and destination of the journey (accident spot). They then identified various intermediate places and potential ways to reach the destinations as the following phase. This was accomplished with the assistance of Google Maps. Furthermore, travel time on these routes was recorded by people who were travelling on them at the same time. When returning to the origin, the identical procedure was followed (hospital). The survey was carried out using auto-rickshaws (three-wheelers) instead of ambulances as means of transportation. This new method eliminates the study's use of real-time ambulances. On these routes, speed and delay tests were undertaken in order to find various factors for a delay in carrying the patient to the hospital. One of the main reason for congestion on roards were no appropriate parking due to which many vehicles were parked asymmetrically on the road. Sometimes they covered almost $80 \%$ of the road while leaving a very narrow passage for the cars and other vehicles that could pass, which results in a massive traffic jam. This chaos and congestion due to the decrease in width of the road results in delaying emergency treatment of the patient. Sometimes the congestion is so much that it covers the entire road and even the main entrances of the hospital. This further causes unnecessary delays in the patient's care. Speed and delay studies may provide us with the present traffic conditions, which may put a check on our hospital's over-reliance on the driver's experience and provided us with dynamic traffic data that can be put to use to enhance the efficiency of the system. In conclusion, the study told us that space for the proper parking should be allocated. One way to avoid the delay is to find the shortest path to reach the required destination. The most important thing is to educate people in general ${ }^{[8]}$.

Another important thing is to bring awareness among the public on the proper use of ambulance facilities. They started a campaign and educate people about the proper use of ambulances, and they found that educating people would reduce ambulance calls. By decreasing the nonserious conditions, the same ambulance will be available for serious conditions, preventing unnecessary death ${ }^{[3]}$.

It is very important to educate the public on how they can facilitate the ambulance. For this, different seminars and conferences can be organized. Different programs involving students can be started highlighting the importance of making way for the ambulance and saving one's life. In general, it is important for the bikers to have their back mirror intact and whenever they heard the ambulance siren should give way to the ambulance. Slowing down and being careful is really important because some people can have a moment of panic and slam on the brakes. It is also proposed that you should move your vehicle to the left (move to the left so an ambulance could pass down). If you can't move left safely, stay where you are and let the emergency vehicle overtake you. It is also important that you avoid driving in your path, and if you have to take any turn, don't take turns suddenly. Another thing that can be done to bring awareness to the public is that we can arrange mock drills. 
These drills can educate people on the sensitivity of the issue. In these drills, the one who gives way to the ambulance can be encouraged by giving some reward ${ }^{[9]}$.

In Pakistan, it is a dilemma where people are not observing day-to-day traffics rules and regulations. To make them understand the importance of giving was to the ambulance and to save someone's life is a difficult task, however if not impossible. In a country like Pakistan, where the majority, even those who are educated, violate the traffic rules is so common. People even think that these rules are useless. Many youngsters are dying in road traffic accidents as they don't follow the traffic rules and there is no strict checking. In this case, the implementation of the law is the key. As rules are rules, and everyone has to follow them. We should all realized our responsibility, and it is also our moral obligation to do as much as we can to save lives. Therefore, the take-home message is "Give way to the ambulance. It could be the only difference between life and death. Today, it may be a stranger. Tomorrow, it could be someone yours."

\section{REFERENCES:}

1. Esplin M. The Golden Hours of Fetal Heart Rate Monitoring: Systematic Approach to the Critical Times of Labor and Delivery. Clinical Obstetrics and Gynecology. 2020;63(3):668-677. Doi: 10.1097/ GRF.0000000000000545

2. Wang $\mathrm{X}, \mathrm{Xu} \mathrm{L}$. The factors underlying drivers' unwillingness to give way to ambulances: An application of an extended theory of planned behavior. Journal of Transport \& Health. 2021; 20:101000. Doi: 10.1016/j.jth.2020.101000

3. Shaikh S, Baig LA, Polkowski M. Effectiveness of media awareness campaigns on the proportion of vehicles that give space to ambulances on roads: An observational study. Pakistan Journal of Medical Sciences. 2017;33(1):221-226. Doi: 10.12669/ pjms.331.12176

4. Uddin Mian N, Malik MZ, Iqbal S, Alvi MA, Memon Z, Chaudhry MA, et al. Determining the potential scalability of transport interventions for improving maternal, child, and newborn health in Pakistan. Health Research Policy and Systems. 2015;13(1):75-83. Doi:0.1186/s12961-015-0044-5

5. Zia N, Shahzad H, Baqir SM, Shaukat S, Ahmad $\mathrm{H}$, Robinson C, et al. Ambulance use in Pakistan: an analysis of surveillance data from emergency departments in Pakistan. BMC Emergency Medicine. 2015;15(2):1-6. Doi:10.1186/1471-227X-15-S2-S9

6. Bhatti JA, Waseem H, Razzak JA. Availability and quality of prehospital care on Pakistani interurban roads. Annals of Advances in Automotive Medicine. 2013; 57:257-264.

7. Rosayyan P, Subramaniam S, Ganesan SI. Decentralized Emergency Service Vehicle Pre-Emption System Using RF Communication and GNSS-Based Geo-Fencing. IEEE Transactions on Intelligent Transportation Systems. 2020. Doi: 10.1109/TITS.2020.3007671.

8. Singh S, Thakur P, Agarwal C. Analysis of traffic conditions in highly urbanized areas: a case of Christian Medical College, Vellore. International Journal of Application or Innovation in Engineering \& Management.2015; 4(2):120-127.
9. Mapuwei TW, Bodhlyera O, Mwambi H. Univariate Time Series Analysis of Short-Term Forecasting Horizons Using Artificial Neural Networks: The Case of Public Ambulance Emergency Preparedness. Journal of Applied Mathematics. 2020. Doi:10.1155/2020/2408698

Submitted for Publication:23-10-2021 Accepted after revision: 25-11-2021 